\title{
Direito Internacional e Turismo: uma introdução
}

\author{
Alberto Pereira dos Santos \\ Danielle Brant ${ }^{\mathrm{b}}$ \\ Rosa Maria Brant ${ }^{c}$
}

\begin{abstract}
Resumo
Este artigo tem como objetivo refletir acerca das interfaces entre o turismo e o direito internacional. 0 direito, como instrumento regulador dos conflitos sociais, mostra-se presente neste processo sob o aspecto do direito internacional do turismo, acrescido das diretivas dos tratados assinados pelo Brasil que firmam disposição relativa ao turismo. Utilizou-se como método a reflexão teórica e a revisão bibliográfica a partir de algumas referências da doutrina jurídica que tratam do direito internacional e de sua relação com o turismo. Os resultados deste trabalho indicam que há intrínseca relação entre o direito internacional e o turismo face ao avanço dos meios de transportes, do processo de globalização com internacionalização da economia e da cultura e, sobretudo, da expansão dos direitos humanos e de sua proteção pelos organismos de direito internacional. A conclusão do estudo indica que há escassez de produção teórica acerca desta temática, em parte pelos profissionais do direito e em parte por estudiosos do turismo. Nesse contexto, o artigo se insere como sucinta contribuição ao debate no meio acadêmico.
\end{abstract}

Palavras-chave: Turismo; Direito internacional; Direitos humanos.

\section{Abstract \\ International law and tourism: an introduction}

This article aims to reflect on the interfaces between tourism and international law. The law, as a regulator of social conflicts, is present in this process under the aspect of international tourism law, in addition to the directives of the agreements signed by Brazil that establish a provision related to tourism. A theoretical reflection and bibliographical review were used as method, based on some references of the legal doctrine that deal with international law and its relationship with tourism. The results of this study indicate that there is an intrinsic relationship between international law and tourism due to the advances in transportation, the globalization process with internationalization of the economy and culture, and, above all, the expansion of human rights and their protection by international law bodies. The conclusion of this study indicates that there is a lack of theoretical production on this theme, by legal professionals and tourism scholars. In this context, this article can be considered a contribution to the debate in academia.

Keywords: Tourism; International law; Human rights.

a. Doutor em Geografia Humana pela Universidade de São Paulo (USP). Professor do Departamento de Turismo da Universidade do Estado do Rio de Janeiro (UERJ). Teresópolis, Rio de Janeiro, Brasil. E-mail: albert.geo@uol.com.br

b. Advogada, graduada em Direito pelo Unifeso. Bacharelanda em Turismo na UERJ. Pós-Graduanda em Direito Processual na Universidade Federal Fluminense (UFF). Niterói, Rio de Janeiro, Brasil. E-mail: brantdanielle@hotmail.com

c. Graduada em Direito pelo Unifeso. Bacharelanda em Turismo na UERJ. Teresópolis, Rio de Janeiro, Brasil. E-mail: rosamariabrant@gmail.com 


\section{Resumen}

\section{Derecho internacional y turismo: una introducción}

Este artículo tiene como objetivo reflexionar acerca de las interfaces entre el turismo y el derecho internacional. El derecho, como instrumento regulador de los conflictos sociales, se muestra presente en este proceso bajo los aspectos del derecho internacional del turismo y de las directivas de los tratados firmados por Brasil que establecen disposiciones relativas al turismo. Se utilizó como método la reflexión teórica y la revisión bibliográfica a partir de algunas referencias de la doctrina jurídica que tratan del derecho internacional y de su relación con el turismo. Los resultados de este trabajo indican que hay intrínseca relación entre el derecho internacional y el turismo frente al avance de los medios de transporte, del proceso de globalización con la internacionalización de la economía y de la cultura y, sobre todo, de la expansión de los derechos humanos y su protección por los organismos de derecho internacional. La conclusión del estudio indica que hay escasez de producción teórica acerca de esta temática, tanto en el área del derecho como en el área del turismo. En ese contexto, el artículo se inserta como sucinta contribución al debate en el medio académico.

Palabras clave: Turismo; Derecho internacional; Derechos humanos.

\section{INTRODUÇÃO}

A recente saída do Reino Unido da União Europeia, em junho de 2016, implicará em aspectos do direito internacional do turismo? Essa indagação suscita interessante e oportuna reflexão acerca das relações entre direito internacional e turismo. Não é nossa intenção, porém, neste sucinto trabalho, dar conta desse recente fato histórico e geopolítico de relações internacionais que, certamente, implicará no turismo internacional. Nosso objetivo, aqui, é bem mais modesto: diríamos que se trata, na verdade, de notas introdutórias acerca das interfaces entre turismo, direitos humanos e direito internacional.

Face ao processo de globalização - avanço nos meios de transportes, tecnologia da informação na sociedade do conhecimento, interdependência econômica e cultural das nações - o turismo internacional tende a crescer. Por outro lado, o papel da Organização das Nações Unidas (ONU), com a permanente política de proteção dos direitos humanos, possibilita o desenvolvimento do direito internacional (Beni, 2003).

Segundo a Organização das Nações Unidas para a Educação, a Ciência e a Cultura (Unesco), em seu relatório sobre educação para o século XXI, a educação continuada é uma premissa que indica a necessidade de permanente formação dos cidadãos e profissionais. Por outro lado, dada a velocidade da inovação do conhecimento, é recomendável aos profissionais ou especialistas de uma determinada área do conhecimento que se aproximem de outras áreas, no sentido de busca da interdisciplinaridade - diálogo com outros especialistas - tendo em vista que os desafios ou problemas humanos não se resolvem a partir do conhecimento isolado de uma determinada área, seja do turismo, do direito, da economia ou da saúde. Em suma, se faz necessário o diálogo e a aproximação teórica entre diversos profissionais e especialistas do conhecimento (Delors, 2007).

Ao sublinhar essas recomendações da Unesco, estamos sinalizando o método escolhido para a elaboração deste sucinto texto. Utilizou-se como método a 
reflexão teórica e revisão bibliográfica a partir de algumas referências da doutrina jurídica que tratam do direito internacional e de sua relação com o turismo. 0 artigo foi pensado e elaborado por autores que atuam na área do direito e da geografia, todos tendo o turismo como congruência teórica, ou o turismo como objeto de estudo inter, multi e transdisciplinar.

De acordo com Morin (2005), a interdisciplinaridade admite os limites de cada disciplina e de seus especialistas, embora, às vezes, ocasione trocas e cooperação entre elas e seus especialistas. Nessa concepção, embora entendam que seus saberes são muito importantes para se analisar um determinado fenômeno, os especialistas têm consciência de que seus conhecimentos são limitados. Por isso, a interdisciplinaridade seria o encontro de vários especialistas para discutir ou resolver um problema complexo que nenhuma disciplina, sozinha, poderia explicar, compreender e resolver.

Nas palavras de Morin (2005, p. 52):

A interdisciplinaridade controla tanto as disciplinas como a ONU controla as nações. Cada uma disciplina pretende primeiro fazer reconhecer a sua soberania territorial e, desse modo, confirmar as fronteiras em vez de desmoroná-las, mesmo que algumas trocas incipientes se efetivem.

Nosso ponto inicial de reflexão para a produção deste escrito se deu a partir do ambiente acadêmico, em 2015, na universidade pública, onde nos encontramos no processo de ensino, aprendizagem e pesquisa na disciplina Turismo e Relações Internacionais do curso de bacharelado em turismo.

Sabemos que as interfaces entre turismo e relações internacionais são muitíssimas, amplas e instigantes. Entretanto, nosso recorte teórico foi delimitado nas interfaces entre turismo, direitos humanos e o direito internacional. Mesmo assim, ainda admitimos que essas interfaces também são amplas. Por isso, e também dados os limites, as características e finalidades deste estudo, nos limitamos modestamente a tecer algumas notas introdutórias acerca da temática em tela.

Ao optarmos por fazer uma introdução acerca das relações entre direito internacional e turismo, alertamos ao leitor, porém, que não espere uma abordagem histórica linear ou um recorte espacial específico. Ou seja, ao buscarmos algumas interfaces, o fizemos de modo que não se privilegiou um estudo de caso local ou regional que implicaria em análise do direito internacional do turismo. Assim sendo, o leitor se deparará, de um lado, com aspectos gerais e internacionais e, de outro, com alguns aspectos nacionais, com notas, en passant, acerca do direito internacional e do turismo no Rio de Janeiro, face ao contexto do megaevento das Olimpíadas Rio 2016.

Sabemos que, de um lado, a temática é ampla, suscitando múltiplas abordagens e, de outro, admitimos que este artigo se limita a introduzir notas acerca das interfaces entre direito internacional e turismo. Embora estando abertos a inevitáveis e bem-vindas críticas, esperamos que este trabalho contribua, em alguma medida, para o debate e a reflexão no processo de educação continuada de profissionais e na formação de novos bacharéis em turismo e em direito. 


\section{PROCEDIMENTOS METODOLÓgICOS E RESULTADOS DO ESTUDO}

Como sublinhamos, o método utilizado neste estudo foi a reflexão teórica a partir de revisão bibliográfica acerca da doutrina jurídica que trata do direito internacional e de suas interfaces com o turismo. Utilizou-se de procedimento metodológico exploratório e descritivo (Gil, 2010). Assim sendo, fizemos breve abordagem do estado da arte acerca da temática objeto de estudo.

Os resultados do estudo se configuraram neste artigo que, para efeito de apresentação, está organizado em três tópicos complementares: "Síntese histórica dos direitos humanos", "Direitos humanos no Estado brasileiro, soberania e proteção do direito internacional" e "Turismo e direito internacional".

Ainda como parte dos resultados, pôde-se entender que existe intrínseca relação entre direito internacional e turismo. Entretanto, este estudo indica que há escassez de produção acadêmica acerca dessa temática.

\section{SÍNTESE HISTÓRICA DOS DIREITOS HUMANOS}

Primeiramente explicitamos que os direitos humanos são aqueles relacionados à liberdade e à igualdade, e que estão positivados no plano internacional. Os doutrinadores concordam que os direitos humanos são jusnaturalistas, isto é, vêm desde o nascimento dos seres humanos. Já os direitos fundamentais são interligados aos direitos humanos e presentes na Constituição Federal, no seu título II, "Dos direitos e garantias fundamentais". A supremacia da Constituição Federal está intimamente ligada ao conceito de soberania do Estado brasileiro. Assim, em regra, os ditames constitucionais nacionais só produzem efeitos a quem está sob a tutela estatal brasileira. Logo, todos os que se encontram em território brasileiro, nacional ou estrangeiro, residentes ou em trânsito no país, pessoas físicas ou jurídicas, terão acesso a todos os direitos e garantias expressos.

Por força do princípio da universalidade dos direitos fundamentais, a maior parte desses direitos são assegurados a qualquer indivíduo, seja ele brasileiro ou não, residente no Brasil ou no exterior. Nessa esteira, segundo Mello (2004, p. 820) "só há direitos fundamentais quando há um texto constitucional escrito e consagrado na jurisdição constitucional que os garante".

Vale sublinhar que, neste estudo, entendemos os "direitos humanos" como inerentes à própria condição humana. Tais direitos, mesmo que não reconhecidos em textos normativos, em razão de exigências morais podem ser reconhecidos em tratados e protocolos com pretensão de universalidade, limitando a atuação estatal. Doutro norte, quando utilizarmos a expressão "direitos fundamentais", estaremos nos referindo a um conjunto de direitos humanos reconhecidos e positivados na esfera do direito constitucional de determinado Estado. Fica, portanto, evidente que direitos humanos e direitos fundamentais não têm o mesmo significado, mas um complementa o outro, porque têm a pessoa humana como destinatária da sua proteção.

Em que pese a contemporaneidade de sua discussão e debate, não nos custa sublinhar, como sugere Dallari (2013), que desde a Antiguidade documentos legislativos revelam a preocupação com a afirmação dos direitos 
fundamentais. Sob o prisma histórico, os direitos humanos surgiram gradualmente na história por meio da lutas de classes em objeção à concentração de poder, às opressões, às desigualdades sociais e ao desrespeito à dignidade da pessoa humana, gerados pela globalização e a intensificação das relações humanas. No processo de construção e desenvolvimento dos direitos humanos, a doutrina jurídica aponta como marco inicial a Magna Carta da Inglaterra, promulgada em 1215, pelo rei João Sem Terra.

Uma longa história ocorreu, antes do século XX, até chegarmos em 1919, quando foi criada a primeira organização internacional denominada Liga das Nações ou Sociedade das Nações, órgão que precede a ONU. Essa Liga teve origem no Tratado de Versalhes, com os países vencedores após a Primeira Guerra Mundial. Seu objetivo consiste em assegurar a paz, a cooperação e a segurança internacional das nações. A Liga das Nações, porém, fracassou com a Segunda Guerra Mundial.

Contudo, a consolidação do direito internacional dos direitos humanos se deu em meados do século XX, como um fenômeno pós-Segunda Guerra Mundial. Nesse sentido, seu desenvolvimento pode ser atribuído às monstruosas violações de direitos humanos da era Hitler e à crença de que parte destas violações poderiam ser prevenidas se um efetivo sistema de proteção internacional de direitos humanos existisse (Piovesan, 2010, p. 121).

Assim, após a Segunda Guerra Mundial, como resposta às atrocidades, destruições, violações aos direitos humanos e sobretudo à negação da dignidade da pessoa humana como valor fonte de todas as relações, em 26 de junho de 1945, foi aprovada pela comunidade internacional a Carta das Nações Unidas, que criou a ONU, destinada a fornecer a base jurídica para a permanente ação conjunta dos Estados em defesa da paz mundial (Dallari, 2013, p. 211).

São intuitos das Nações Unidas expressos no art. 1ํ da Carta:

1) Manter a paz e a segurança internacionais e para esse fim: tomar medidas coletivas eficazes para prevenir e afastar ameaças à paz e reprimir os atos de agressão, ou outra qualquer ruptura da paz e chegar, por meios pacíficos, e em conformidade com os princípios da justiça e do direito internacional, a um ajustamento ou solução das controvérsias ou situações internacionais que possam levar a uma perturbação da paz; 2) Desenvolver relações de amizade entre as nações baseadas no respeito do princípio da igualdade de direitos e da autodeterminação dos povos, e tomar outras medidas apropriadas ao fortalecimento da paz universal; 3) Realizar a cooperação internacional, resolvendo os problemas internacionais de caráter econômico, social, cultural ou humanitário, promovendo e estimulando o respeito pelos direitos do homem e pelas liberdades fundamentais para todos, sem distinção de raça, sexo, língua ou religião; 4) Ser um centro destinado a harmonizar a ação das nações para a consecução desses objetivos comuns.

A criação das Nações Unidas demarca o movimento de internacionalização e promoção dos direitos humanos, onde os Estados membros passam a reconhecer que os direitos essenciais da pessoa humana não têm mais uma exclusiva preocupação com a jurisdição doméstica, mas, ao contrário, constituem uma preocupação global. 
Respondendo a essa preocupação, foi criada a Comissão dos Direitos Humanos, em 1946, que preparou a Declaração Universal dos Direitos Humanos, aprovada em 1948, e na qual ocorreu um amadurecimento das relações internacionais em relação ao preconceito de raça, cor, gênero, idioma, opiniões políticas, nacionalidade, origem social (UNHCR, 2017).

A Comissão dos Direitos Humanos não teve muito êxito em alcançar seus objetivos no que tange à proteção dos direitos humanos, principalmente depois do atentado de 11 de setembro de 2001, nos Estados Unidos. A comissão foi logo substituída pelo Conselho de Direitos Humanos, aprovado pela resolução 60/251, de 03/2006, na Assembleia Geral das Nações Unidas (AGNU).

O Conselho de Direitos Humanos é um órgão intergovernamental que forma parte do sistema das Nações Unidas e que está composto por 47 Estados Membros responsáveis pelo fortalecimento, promoção e proteção dos direitos humanos no mundo. Foi criado pela Assembleia Geral das Nações Unidas em 15 de março de 2006, com o objetivo principal de considerar as situações de violação dos direitos humanos e fazer recomendações a respeito destes problemas. (Simuna, 2015)

Para melhor entendimento, os direitos humanos foram divididos em gerações. Alguns doutrinadores falam em três gerações, outros, em quatro. Essas dimensões de direitos humanos foram separadas conforme o lema da Revolução Francesa de 1789, liberté, égalité, fraternité, com liberdade correspondendo à primeira geração, igualdade à segunda e fraternidade à terceira, sobrevindo, somente anos depois, a quarta e a quinta geração de direitos (Bobbio, citado por Lima, 2003).

A primeira geração é marcada pelos direitos humanos civis e políticos. Portanto, os direitos de primeira geração estão ligados à autonomia, ou seja, à liberdade do homem em decidir sobre o seu próprio destino, vida e consciência, vedando ao Estado impor proibições naquilo que concerne à pessoalidade de cada um, tanto no âmbito físico quanto moral. Como exemplos, pode-se citar o direito à vida, à liberdade, à propriedade, à liberdade de expressão, à participação política e religiosa, à inviolabilidade de domicílio, à liberdade de reunião, entre outros.

Já a segunda geração é vista sob a perspectiva dos direitos econômicos, sociais e culturais. A partir da percepção de que o cidadão sozinho não é capaz de garantir uma vida digna, o Estado é chamado para ter deveres perante os homens. No viés dos direitos fundamentais de segunda geração, a proposta que se tem é a de um equilíbrio real na relação entre Estado e cidadão, fazendo com que o ente estatal, que detém o maior poder (econômico, político e jurídico) seja um sujeito não apenas com direitos, mas também deveres, permitindo ao cidadão viver com dignidade, não apenas pelos seus próprios meios, mas também pelos meios ofertados pelo Estado. Assim, dizem respeito aos direitos fundamentais de segunda geração a assistência social, saúde, educação, trabalho, lazer etc.

E, por fim, os direitos de terceira geração consagram o princípio da fraternidade, colaboração entre os povos, preocupação ambiental, progresso, paz. Os direitos de quarta geração ainda são vistos sob perspectivas diversas pelos 
autores: uns dizem que tais direitos existem, outros afirmam que ainda estamos na terceira geração.

\section{DIREITOS HUMANOS NO ESTADO BRASILEIRO, SOBERANIA E A PROTEÇÃO DO DIREITO INTERNACIONAL}

A institucionalização dos direitos humanos pelo direito brasileiro foi dada pela Constituição Federal de 1988, que demarca, no âmbito jurídico, o processo de democratização do Estado brasileiro ao romper com o regime autoritário militar, instaurado em 1964. Em consequência do processo de democratização, a Magna Carta representa indiscutível avanço na consolidação legislativa de garantias e direitos fundamentais e na proteção de setores vulneráveis da sociedade brasileira. Isso porque, a partir dela, os direitos humanos ganham relevo extraordinário, situando-se a Constituição de 1988 como o documento mais abrangente e pormenorizado sobre os direitos humanos adotado no Brasil (Piovesan, 2010).

Esta norma constitucional simboliza a reinserção do Brasil no âmbito internacional. Isto porque trata-se da primeira Constituição brasileira a consagrar um universo de princípios para guiar o país no cenário internacional, fixando valores a orientar a agenda internacional, garantindo um futuro mais seguro e sustentável.

Por sua vez, as organizações internacionais também são associações de sujeitos de direito internacional, ou seja, constituídas por estados. Essas organizações, que decorrem do crescimento das relações internacionais e da cooperação necessária entre as nações, têm objetivos como: obtenção ou manutenção da paz, resolução de conflitos armados, desenvolvimento econômico e social etc.

Com objetivos específicos ou generalizados, as organizações internacionais podem ser divididas em intergovernamentais (globais e regionais) e não governamentais. São exemplos de organizações globais a Organização das Nações Unidas (ONU), cujo objetivo generalizado nasce da Carta das Nações Unidas, com a assinatura de 50 países (Pinto, 2017), e a Organização das Nações Unidas para a Educação, a Ciência e Cultura (Unesco), com objetivo específico, visando à cooperação e reafirmando a Declaração Universal dos Direitos Humanos, com dois pactos de 1966, o dos direitos civis e políticos e o dos direitos econômicos, sociais e culturais (Unesco, 2001). Como organização regional, pode-se citar a Organização dos Estados Americanos (OEA), de objetivo generalizado, e, no caso das organizações não governamentais, o Greenpeace, fundado em 1972 com um objetivo específico.

Embora os Estados tenham suas soberanias nacionais protegidas pelo direito internacional, vale sublinhar que as organizações intergovernamentais globais e regionais, bem com as não governamentais, também são atores no cenário das relações internacionais e, às vezes, interferem ou influenciam, em certa medida, nas políticas dos Estados nacionais (Pecequilo, 2004; Sarfati, 2005).

A ideia ou conceito de soberania tem origem no ano de 1648, no Tratado de Paz de Vestfália. A soberania estatal é abordada como fonte originária de todo o poder exercido pelo Estado, poder este com conotação de incontestável e incontrastável. Nessa perspectiva, o governante pode fazer o que bem entender 
dentro de seu território, de tal modo que nenhum outro governante ou força política terá o direito de intervir (Sarfati, 2005).

Entretanto, na atualidade, especialmente após a invasão das forças norte-americanas no contexto da Guerra da Iugoslávia (1994), há que se questionar tal definição, considerando a nova ordem internacional, no pós-modernismo, que passa a exigir do Estado um pensamento global, com intuito de concretizar uma comunidade internacional em seu sentido mais amplo, intentando a satisfação e a congruência de interesses divergentes por meio da cooperação entre os Estados face à necessidade de interdependência por motivos de ordem econômica, política e social (Huntington, 1997).

Por outro lado, há que se levar em conta também a dimensão geopolítica do turismo, tendo em vista que as rivalidades de interesses econômicos e políticos, tanto de empresas quanto de governos, interferem na dinâmica dos fluxos turísticos (Hoerner, 2001). Ademais, nas teorias de relações internacionais, essas disputas turísticas também podem ser entendidas como aspectos políticos numa "sociedade anárquica", ou seja, numa sociedade mundial na qual existe uma certa anarquia ou ausência de governo, porém com relativa governança internacional (Bull, 2002).

Sublinhamos que o turismo também pode ser considerado como soft power, isto é, poder brando nas relações internacionais, como poder de atração turística fomentado a partir de megaeventos internacionais, a exemplo da Copa do Mundo e dos Jogos Olímpicos. De acordo com Joseph Nye,

existe um modo indireto de exercer o poder. Na política mundial, é possível que um país obtenha os resultados que quer porque os outros desejam acompanhá-lo, admirando seus valores, imitando-lhe o exemplo, aspirando ao seu nível de prosperidade e liberdade. Neste sentido, é igualmente tão importante estabelecer a agenda na política mundial e atrair os outros quanto força-los a mudar mediante a ameaça ou o uso das armas militares ou econômicas. A este aspecto do poder - levar os outros a querer o que você quer - dou o nome de poder brando. (Nye, 2002, p. 36, grifo nosso)

Estudiosos do turismo internacional têm contribuído para o entendimento das interfaces entre turismo e relações internacionais. De acordo com Pieri e Panosso Netto (2015, p. 63):

Ao analisar o turismo internacional nesse contexto político e econômico atual, percebe-se que não somente a sensação de ordem multipolar no mundo, mas também a melhoria nas condições de vida de grande parcela da população mundial, especialmente das novas potências emergentes, contribui nas condições que esta enorme camada populacional possui para usufruir do turismo.

Sob esse contexto, os Estados têm conferido uma maior preocupação com os compromissos assumidos no âmbito externo, ou seja, com suas relações internacionais, do que com a questão de seu poder soberano absoluto e inatingível, de modo que a soberania está se limitando em razão da necessidade de interdependência entre as nações, isto é, com os pactos, tratados e compromissos assumidos no âmbito externo em resposta a questões de ordem internacional, como a globalização, o desenvolvimento econômico e industrial, o respeito 
mútuo entre os povos, a busca da paz mundial, o progresso humanitário, entre outros (Pecequilo, 2004).

Assim sendo, o Estado que violar direitos humanos poderá ser responsabilizado perante a comunidade internacional por intermédio de cortes regionais, como a Corte Interamericana de Direitos Humanos, ou de comitês internacionais, como o Comitê dos Direitos Humanos, criado pelo Pacto Internacional dos Direitos Civis e Políticos. Dentro dessa lógica, o indivíduo que tiver sua dignidade violada e não conseguir a efetiva tutela poderá buscar (direta ou indiretamente) cortes e comitês internacionais para garantir sua devida proteção. Ademais, o dirigente político que conduzir o país a práticas de crimes contra a humanidade também poderá ser julgado e condenado pelo Tribunal Penal Internacional (Flumian, 2012, p. 1134).

Ao mesmo tempo, as organizações internacionais apoiam o turismo por sua contribuição à paz mundial, pelos benefícios da ligação de diferentes povos e culturas e pelas vantagens econômicas que dele podem decorrer.

Nesse contexto, a Organização Mundial do Turismo (OMT), antiga União Internacional de Organizações Oficiais de Viagens (Iuoto), teve sua origem no ano de 1925 como uma organização internacional não governamental que continha associações privadas e governamentais de turismo (Almeida, 2001). Já em 2003, tornou-se uma agência especializada das Nações Unidas. Sua missão consiste em promover o turismo sustentável, responsável e universalmente acessível como fomentador do desenvolvimento inclusivo.

0 turismo se tornou um dos principais atores no comércio internacional e representa uma importante fonte de renda para muitos países em desenvolvimento. Como agência da ONU dedicada ao turismo, a OMT insiste que os países em desenvolvimento podem se beneficiar do turismo, ajudando na colocação de destinos nos mercados nacionais e internacionais de forma sustentável (Beni, 2003).

Na esfera do Estado brasileiro, a Constituição Federal contribui para o turismo no seu Art. 180, ao estabelecer que: "a União, os Estados, o Distrito Federal e os Municípios promoverão e incentivarão o turismo como fator de desenvolvimento social e econômico". Nessa perspectiva, o Ministério do Turismo (MTur) é o órgão federal brasileiro responsável pelo planejamento e execução das políticas públicas do turismo em território nacional, bem como tem suas incumbências no processo de inserção do turismo no cenário internacional em parceria com o Ministério das Relações Exteriores. Ambos são responsáveis, por exemplo, por todo o processo de promoção dos megaeventos internacionais, a exemplo da Copa do Mundo, realizada em 2014, e das Olimpíadas Rio 2016, em parceria com os governos estadual e municipal do Rio de Janeiro.

\section{TURISMO E O DIREITO INTERNACIONAL}

A promulgação do Código Mundial de Ética do Turismo, em 1999, elaborado pela OMT, é uma referência para o desenvolvimento sustentável e responsável da atividade turística no âmbito mundial. Contudo, sublinhamos que vários documentos internacionais antecederam ao Código, a exemplo da Declaração de Manila sobre o Turismo Mundial de 1980, a Carta do Turismo, o Código do Turista, de 1985, e a Resolução 364 da Assembleia Geral de 1997. 
A atividade turística teve seu ápice no século XX e vem sendo desenvolvida até os dias atuais, sendo cada vez mais valorizada, não somente como atividade econômica, mas sobretudo como atividade social e cultural no cenário das relações internacionais (Barreto, Burgos, \& Frenkel, 2003).

Uma questão de enorme relevância na interface do turismo com o direito internacional, que merece a atenção e preocupação dos profissionais do turismo, diz respeito ao chamado "turismo sexual" e à exploração sexual infantil, isto é, os fluxos de turistas nacionais e internacionais que realizam viagens e as utilizam como meio para a busca do prazer sexual com os chamados profissionais do sexo (garotas e garotos de programa), muitas vezes com a exploração sexual de crianças e adolescentes.

Entretanto, a Comunidade Internacional, por meio de vários documentos (Convenção sobre os Direitos da Criança, de 1990; Resolução da 11 ${ }^{\text {a }}$ Assembleia Geral da OMT sobre prevenção do turismo sexual organizado, de 1995; Declaração de Estocolmo contra a exploração sexual de crianças para fins comerciais, de 1996, entre outros), combate à exploração sexual de crianças e adolescentes.

Nesse mesmo sentido, o Código Mundial de Ética no Turismo, em seu artigo $2^{\circ}$, desestimula e combate o turismo sexual:

exploração dos seres humanos sob todas as suas formas, principalmente sexual, e especialmente no caso das crianças, vai contra os objetivos fundamentais do turismo e constitui a sua própria negação. Portanto, e em conformidade com o Direito Internacional, ela deve ser rigorosamente combatida com a cooperação de todos os Estados envolvidos e sancionada sem concessões pelas legislações nacionais, quer dos países visitados, quer dos países de origem dos atores desses atos, mesmo quando estes são executados no estrangeiro. (Organização Mundial de Turismo, 2016)

O turismo sexual deve ser analisado em sua dialética, levando-se em conta os aspectos históricos, coloniais, migratórios, políticos e sociais. Entretanto, de acordo com o pesquisador Arim Soares do Bem:

O turismo sexual, embora esteja disseminado como prática cada vez mais visível nas sociedades contemporâneas, não pode ser considerado simplesmente um segmento a mais da atividade turística (por pressupor a existência de um mercado configurado), mas uma de suas perniciosas deformações. Sua existência reflete, de fato, a preexistência de problemas bem mais profundos, os quais, por sua vez, estão ancorados no coração das sociedades receptoras e emissoras de turistas. (Soares do Bem, 2005, p. 19)

Por outro lado, a OMT insiste em revalorizar a imagem do turista a fim de fortalecer a economia moderna, e embora o turismo interno não perca sua força, existe uma intensa investida na internacionalização do turismo. Há também uma grande preocupação com o aspecto social do turismo. Nesse sentido, a população visitada deve acolher o turista sem preconceito, e o turista deve respeitar os valores locais.

O Quadro 1, a seguir, demonstra o peso financeiro do turismo internacional. 
Quadro 1 - Chegadas e receitas do turismo internacional de 13 países que também se beneficiam de um turismo interno forte

\begin{tabular}{|c|c|c|c|c|c|}
\hline \multirow{2}{*}{$\begin{array}{l}\text { Parâmetros/ } \\
\text { Países }\end{array}$} & \multicolumn{2}{|c|}{ Chegadas (2003) } & \multicolumn{2}{|c|}{ Receitas (2000) } & \multirow{2}{*}{$\begin{array}{c}\text { Chegadas } \\
\text { de } 1990 \text { a } 2003 \\
\%\end{array}$} \\
\hline & Milhões & $\%$ & Milhões de dólares & $\%$ & \\
\hline França & 75 & 11 & 29.900 & 6,3 & +43 \\
\hline Espanha & 49,5 & 7 & 31.000 & 6,5 & +45 \\
\hline Estados Unidos & 40,4 & 6 & 85.200 & 17,8 & $+2,5$ \\
\hline Itália & 40 & 6 & 27.400 & 5,7 & +49 \\
\hline China & 40 & 6 & 24.000 & 5 & +135 \\
\hline Reino Unido & 24,8 & 4 & 19.500 & 4 & +38 \\
\hline Áustria & 19,1 & 3 & 11.400 & 2,4 & $+0,5$ \\
\hline Alemanha & 18,3 & 3 & 17.800 & 3,7 & $+7,5$ \\
\hline Canadá & 17,5 & 2,5 & 10.200 & 2,1 & $+15,5$ \\
\hline Suíça & 10 & 1,5 & 7.300 & 1,5 & -25 \\
\hline Países Baixos & 9,3 & 1,5 & 7.000 & 1,4 & +6 \\
\hline Bélgica & 6,7 & 1 & 7.000 & 1,4 & +58 \\
\hline Austrália & 4,3 & 0,5 & 8.400 & 1,8 & $+95,5$ \\
\hline Total & 355 & 53 & 276.100 & 57,9 & +34 \\
\hline
\end{tabular}

A principal instituição global de finanças e comercio é o FMI, que contribui para o turismo internacional a ponto de tentar resolver as divergências políticas, que são um fator determinante para a escolha do destino turístico junto à saúde financeira do país, que está intimamente ligada ao poder de compra do turista e associada ao favorecimento do consumo entre as classes menos favorecidas, diante das políticas de transparência diretas e com atuação do Estado (Pieri \& Panosso Netto, 2015).

0 turismo internacional vincula-se ao consumo de produtos turísticos no estrangeiro, ou seja, o ato de indivíduos de um Estado consumirem "turisticamente" em outro Estado (Almeida, 2001). Daí a necessidade da concordância e paz entre os Estados, da garantia de liberdade à saída de cidadãos e também da aceitação dos Estados fornecedores de produtos turísticos.

Nessa perspectiva, sob a ótica do direito internacional privado, com a evolução da tecnologia, o turismo envolve o processo desde o consumidor até a compra à distância do produto turístico, sem realmente conhecê-lo. 0 consumidor está, portanto, em situação de vulnerabilidade ou inferioridade, podendo ser alvo de publicidade enganosa, se deparando, por exemplo, com a falência da empresa prestadora dos serviços que adquiriu. A necessidade de uma proteção eficaz do turista mostra-se obrigatória na atual circunstância de desenvolvimento turístico acelerado, movimentação de grandes somas de dinheiro e número cada vez maior de turistas.

Outro ponto importante diz respeito à venda dos produtos turísticos em sites internacionais. Surge aqui a dúvida sobre qual será o foro caso ocorra algum problema com a viagem. Para os países que possuem tratados ou acordos com o Brasil, os problemas serão resolvidos na jurisdição brasileira. Já os países não 
signatários de tratados com o Brasil, terão seus conflitos resolvidos fora do país, como é o caso da Alemanha. Um bom exemplo é a compra de um cruzeiro internacional em um site italiano: como a Itália é signatária do mesmo tratado que o Brasil, o foro será brasileiro.

O turismo também concorre para o direito no seu aspecto de ampliação para uma nacionalidade global. Nesse caso, regerá a lei do país em questão para realizar a naturalização. De acordo com artigo 12, I, a Constituição da República Federativa do Brasil, sob o critério jus solis (origem territorial), tem como regra que todo nascido em território nacional será brasileiro nato. Portanto, se os pais chegam ao Brasil a turismo e o filho nasce em território brasileiro, o filho, mesmo de pais estrangeiros, será brasileiro nato. A mesma situação vale para os filhos de pais estrangeiros nascidos no exterior, seguindo o critério jus sanguinis (direito de sangue).

Conforme o artigo 12, I, da Constituição, são brasileiros natos, ou seja, indivíduos que adquirem a nacionalidade originária brasileira:

1)“os nascidos na República Federativa do Brasil, ainda que de pais estrangeiros, desde que estes não estejam a serviço de seu país”. Por esse critério, o Brasil adota a regra do jus soli, ou seja, são brasileiros natos os indivíduos que nascem em território brasileiro. 0 termo "território" abrange tanto o território propriamente dito como navios e aeronaves de guerra, navios mercantes, aeronaves, espaço aéreo e mar territorial brasileiros. Entretanto, a Constituição apresenta uma exceção à regra do jus soli: os nascidos no território brasileiro, filhos de pais estrangeiros, desde que qualquer um deles esteja a serviço de seu país - o que compreende carreira diplomática, consular, serviço para órgão da administração pública direta ou indireta do Estado estrangeiro -, não terão a nacionalidade originária brasileira. Vale destacar que não se aplica essa exceção ao estrangeiro que está no Brasil a serviço de um órgão ou entidade internacional que não esteja representando oficialmente seu país. Logo, adota-se, nesse caso, a regra da territorialidade, e o filho desse estrangeiro será considerado brasileiro nato.

2) “os nascidos no estrangeiro, de pai brasileiro ou mãe brasileira, desde que qualquer um deles esteja a serviço da República Federativa do Brasil”. Nessa hipótese de aquisição da nacionalidade originária brasileira, o Brasil não adota a regra do jus soli, mas sim a consanguinidade somada ao caráter funcional. 0 raciocínio é simples: se estrangeiros que estão no Brasil a serviço de seu país concebem no território brasileiro seu filho e este não é considerado brasileiro, a recíproca deve ser a mesma, ou seja, o filho de pai brasileiro ou mãe brasileira que está em país estrangeiro a serviço do Brasil tem de ser considerado brasileiro nato. Nesse caso, o indivíduo é brasileiro sem ter nascido em território brasileiro (aplicação do jus sanguinis somado ao critério funcional).

3)“os nascidos no estrangeiro de pai e mãe brasileira, desde que sejam registrados em repartição brasileira competente ou que venham a residir na República Federativa do Brasil e optem, em qualquer tempo, depois de atingida a maioridade, pela nacionalidade brasileira" (redação dada 
pela EC 54/07). Assim sendo, a nova redação retoma em parte o texto constitucional que vigorava até a edição da Emenda Constitucional de Revisão 3, de 1994, que proibiu os filhos de pai ou mãe brasileiros que não estivessem representando o Brasil e que nascessem no estrangeiro de serem registrados na repartição competente (embaixada ou consulado). Atualmente, contudo, a Constituição admite o registro na repartição brasileira competente. Alternativamente a esta possibilidade, a norma constitucional também admite a aquisição da nacionalidade originária ao brasileiro que voltar a residir no país e optar, em qualquer tempo, após completar 18 anos, pela nacionalidade brasileira. Questão interessante é a situação dos nascidos no estrangeiro, filhos de pai brasileiro ou mãe brasileira, que nasceram entre a edição da Emenda de Revisão 3 e a Emenda Constitucional 54, ou seja, entre 7 de junho de 1994 e 20 de setembro de 2007. Para resolver esta situação, a mesma Emenda Constitucional 54/07 criou o artigo 95 dos atos das disposições transitórias: nesses casos, tais pessoas poderão ser registradas em repartição diplomática ou consular brasileira competente ou em ofício de registro, se vierem a residir na República Federativa do Brasil.

Outro quesito é a viagem do menor: de acordo com o art. 83 do Estatuto da Criança e do Adolescente (ECA), crianças de até 12 anos não podem viajar fora da comarca desacompanhadas dos pais ou responsável sem expressa autorização judicial. Em viagens internacionais, a autorização legal é dispensável, quando as crianças e adolescentes (entre 12 e 18 anos incompletos), apresentarem documento que comprove a filiação ou parentesco com o responsável, certidão de nascimento ou documentos de viagens válidos. E, em caso de viagem na companhia de somente um dos pais, o deslocamento só será autorizado por meio de um documento com firma reconhecida do outro.

Brasileiros que ainda não completaram 18 anos podem sair do país acompanhados por estrangeiros, residentes ou domiciliados no exterior, desde que com autorização judicial reconhecida em cartório (art. 85 do ECA). A exceção é para os estrangeiros que sejam genitores do menor.

Outro direito fundamental é o direito ao lazer, constitucionalmente garantido pelo artigo 6․․ Ao lado dos direitos individuais, a Constituição impõe aos poderes públicos atividades de bem-estar e pleno desenvolvimento da capacidade humana, sobretudo para as pessoas mais carentes de recursos, que não têm o poder de conquistá-las com o esforço de seu trabalho. Vale lembrar que, embora o turismo possa ser desvinculado do lazer, tem na sua prática modalidades diversas que podem envolve-lo (Silva, 2005).

Como definido por Badaró (2006), o turismo é um fenômeno social que consiste no deslocamento voluntário das pessoas por motivo de recreação, descanso, tempo livre, saindo do local de residência para outro à procura do lazer.

A prática do lazer deve ser acompanhada de atitudes que remetem ao turismo sustentável. Tanto o lazer quanto o meio ambiente saudável se constituem como direitos fundamentais, conforme a Constituição Federal (Silva, 2002). Em nível mundial, o turismo sustentável também está indicado no artigo $3^{\circ}$ do Código Mundial de Ética no Turismo: 
É dever de todos os agentes envolvidos no desenvolvimento turístico salvaguardar o ambiente e os recursos naturais, na perspectiva de um crescimento econômico sadio, contínuo e sustentável, capaz de satisfazer equitativamente as necessidades e as aspirações das gerações presentes e futuras.

Levando em conta os aspectos do direito e do Código Mundial de Ética no Turismo, na cidade do Rio de Janeiro foi posto em prática o projeto SOS Turista, criado pela Secretaria de Estado de Turismo como um meio para solucionar problemas que envolvam turistas nacionais ou estrangeiros dentro do estado do Rio de Janeiro. Esse projeto foi realizado a partir da Organização Mundial do Turismo (OMT) e consolidado com orientações do Programa de Proteção e Defesa do Consumidor (Procon), da Delegacia Especial de Apoio ao Turista (Deat), da Secretaria de Estado de Segurança Pública e da Agência Nacional de Aviação Civil (Anac).

Por outro lado, a Secretaria de Estado de Turismo apoia o serviço gratuito "Rio Amigo", onde qualquer estrangeiro pode telefonar para um número e ser direcionado para ligação em seu idioma. Há sete idiomas disponíveis: francês, inglês, espanhol, italiano, alemão, russo e coreano. Esses esforços visam tornar a estada no Rio de Janeiro mais segura, aumentando as chances de que o turista estrangeiro e de outros estados do Brasil repita a viagem.

Entre os problemas usuais enfrentados pelos turistas, estão as dificuldades com o voo internacional, que envolve uma última destinação ou parada em país diferente daquele de origem do voo. A tutela dos voos internacionais submete-nos à convenção de Varsóvia e, nos voos nacionais, ao Código Brasileiro da Aeronáutica (CBA). De acordo com o art. 287 do CBA, o transporte aéreo internacional é regido pelas convenções internacionais. Para a convenção valer no Brasil, segue o art. 49 da Constituição, sendo de competência restrita ao Congresso Nacional resolver sobre os tratados. Por sua vez, a celebração dos tratados compete ao presidente da República (art. 84 da Constituição) e posteriormente ao Congresso Nacional, que pode avalizar ou não a decisão.

No tocante à bagagem do turista, a Convenção de Varsóvia foi promulgada pelo Decreto no 20.703/31, com alterações do protocolo de Haia pelo Decreto no 56.463/65. Nos voos internacionais, é definido o limite de aproximadamente US\$20,00 por quilo de bagagem despachada perdida (dentro do meio de hospedagem) ou extraviada (perda no transporte), e US $\$ 400,00$ por passageiro com referência à bagagem de mão, com prazo de 30 dias para reclamação e 30 dias para pagamento. 0 direito a transporte de bagagens gratuitas limita-se a $30 \mathrm{~kg}$ em voos de primeira classe, e de $20 \mathrm{~kg}$ em voos de segunda classe, podendo ser cobrado, acima desse limite, 1\% da tarifa básica por quilo, com arredondamento de frações para cima. Em caso de dano, havendo dolo (intenção de causar o dano ou conhecimento dos riscos assumidos), caberá indenização por danos materiais, ou morais, em caso de sentimento de desconforto e/ou constrangimento.

O Acordo de Schengen é um tratado feito entre os países europeus, com a política de abertura das fronteiras e a livre circulação de pessoas entre os países signatários. Para os turistas de países que não fazem parte da Europa ou que não estão integrados no acordo de Schengen, o documento válido é sempre o passaporte. Os cidadãos brasileiros não necessitam de visto para entrar nos países 
europeus que fazem parte do tratado caso estejam em uma viagem de turismo que dure no máximo 90 dias.

A isenção de visto não exclui algumas exigências ao turista brasileiro para entrar nestes países, tais como: passagem aérea de ida e volta com permanência máxima de 90 dias, comprovante de hospedagem, passaporte com validade superior a 6 meses, plano de assistência médica internacional com cobertura mínima de $€ 30.000,00$ e comprovante financeiro para se manter durante a estada (dinheiro ou cartão de credito internacional).

Vale ressaltar que o Tratado da União Europeia, assinado em 1992, também chamado Tratado de Maastricht, criou a União Europeia, que entrou em vigor em 1993, gerando uma reforma institucional nas competências das comunidades europeias. $\mathrm{O}$ tratado instituiu a cidadania europeia e a prevalência do euro, e a comunidade econômica europeia passou a ser chamada comunidade europeia, integrando politicamente os países (Martín \& Nogueras, 2010).

O tratado foi um marco para a integração europeia. No âmbito interno, a união encontrava insatisfação popular em razão de sua condução política elitizada, concentrada nos chefes de Estado e afastadas dos cidadãos. O tratado, porém, incluiu como pilar comunitário o chamado espaço de liberdade, segurança e justiça, conhecido como Acordo de Schengen, proporcionando a adoção do método comunitário, ou supranacional, nas decisões referentes ao sistema de livre circulação de pessoas sem barreiras, que antes era de caráter intergovernamental (Martín \& Nogueras, 2010).

Já o Mercado Comum do Sul (Mercosul) foi instituído pelo Tratado de Assunção, em março de 1991, entre Argentina, Brasil, Paraguai e Uruguai, com o objetivo de criar um mercado comum entre esses países. Mais tarde, em 1994, com a assinatura do Tratado de Ouro Preto, o Tratado de Assunção foi reconhecido jurídica e internacionalmente como uma organização internacional nos moldes da União Europeia. Onde ocorre a livre circulação de bens, pessoas, serviços e capitais, seus países membros não têm interdependência, o que prevalece são os interesses nacionais, salvo em questões internacionais em que os países membro decidam por tomar decisões comuns. Em 2014, também foi assinada a Carta de Brasília, que reconhece a proteção do consumidor turista como importante ferramenta de cidadania, paz e segurança jurídica entre as nações. A Secretaria Nacional do Consumidor, do Ministério da Justiça, visa garantir ao consumidor turista internacional o direito de ser ouvido e atendido, mesmo fora de seu país, na perspectiva do avanço para a cidadania e incentivo ao mercado envolvido.

0 direito contribui como instrumento regulador dos conflitos sociais, mostrando-se presente seja sob o aspecto do direito internacional do turismo, seja do ponto de ampliação e desenvolvimento do turismo pela integração dos países com os seus tratados. E a indústria do turismo cumpre um papel importante no cenário internacional, pois produz excelentes resultados econômicos, além de reforçar a paz e segurança mundial, porque, para proporcionar um turismo confortável, é necessário ter boas relações internacionais (Barreto et al., 2003).

\section{CONSIDERAÇÕES FINAIS}

Este artigo teve como objetivo tecer uma reflexão introdutória acerca das interfaces entre direito internacional e turismo. Abordou-se uma síntese histórica dos 
direitos humanos, aspectos do Estado brasileiro no tocante à institucionalização desses direitos no contexto de sua soberania e a proteção do direito internacional.

A primeira normatização da atividade turística ocorreu na França, onde o lazer foi visto como direito fundamental. A partir daí, foram se consolidando as relações entre direito internacional e turismo, capazes de reativar as relações de reciprocidade entre os países envolvidos, de modo que o turismo pode aparecer excludente do intervencionismo estatal.

0 turismo, comparado com outras atividades, pode ameaçar a ordem pública, e o direito, por sua vez, esforça-se para solucionar eventuais tipos de desordem. Diferentes exemplos de ameaças à ordem pública quando se trata da área do turismo poderiam ser citados, como a poluição, que coloca em perigo a higiene e o meio ambiente (fauna e flora) e os impactos negativos sobre os parques temáticos que podem colocar em risco todo um meio ambiente, bem como abalar a tranquilidade. 0 turismo é uma atividade consumidora de espaços raros e frágeis, como áreas de montanhas, litoral e outros locais de reservas ambientais. Convém à área do direito zelar por esses espaços, impondo limites jurídicos ao turismo enquanto atividade consumidora e estabelecendo garantias do direito ambiental.

O direito assegura a importância do turismo e mantém a garantia da segurança, da tranquilidade e da saúde pública, visto que, sob vários aspectos, a atividade turística afeta a coletividade, ou seja, a sociedade requer um instrumento regulador para si.

A vontade de divulgar o turismo no corpo social também é uma fonte de crescimento das normas jurídicas. Como é relatado na França, o intervencionismo estatal, com a normatização das férias pagas, em 1936, foi uma condição necessária para a divulgação do turismo. Os exemplos foram seguidos pela Itália e Alemanha, com a divulgação do programa "L’ère des loisirs", que estudava meios de inclusão do lazer nas atividades trabalhistas, buscando maior produtividade e alegria no ambiente laboral.

Os tratados internacionais eram praticamente a única forma de progresso, ainda lento, do turismo internacional. Esses acordos só prosperavam graças aos constantes auxílios de organizações que faziam toda a negociação entre os Estados. Foi a OMT que passou a desempenhar papel fundamental nas negociações e no desenvolvimento eficaz do turismo internacional. Ressalta-se que os Estados não são obrigados a aceitarem estrangeiros em seu território, no entanto, uma vez que os admitam, terão deveres resultantes do direito internacional.

As condições de permanência de um estrangeiro no território brasileiro são regidas pelo Estatuto do Estrangeiro (Lei no 6.815/1980, com as alterações trazidas pela Lei no 6.964/1981, e regulamentada pelo Decreto no 86.715/1981), sendo permitido que o estrangeiro entre no país por meio do visto de entrada, registrado em passaporte.

No caso do Brasil, vale sublinhar o fortalecimento das relações entre direito e turismo no governo do presidente Luiz Inácio Lula da Silva, com a assinatura da Lei 11.771/08, conhecida como Lei Geral do Turismo (LGT). Essa lei reuniu várias normas para o setor turístico antes dispersas. A lei regula e disciplina a prestação de serviço do turismo por meio de cadastros, classificação e fiscalização. 0 objetivo de tal política nacional foi agregar cada vez mais ao turismo, tanto no âmbito nacional quanto internacional, por meio de divulgação dos destinos e 
maior organização, priorizando a conservação do meio ambiente, do patrimônio cultural e histórico e a garantia da dignidade e do bem-estar da pessoa humana na prática das atividades turísticas.

Com o advento da globalização, o turismo se expandiu, dando margem ao desenvolvimento do direito internacional do turismo, que, apoiado nas organizações internacionais, notadamente ONU, OMT e Unesco, considera e busca promover a atividade turística "como um dos elementos primordiais para a consolidação da paz entre os povos, uma vez que o fluxo de turistas faz crescer sentimentos de amizade, respeito e cooperação entre países e entre populações de uma mesma nação" (ONU, 2015).

A recente saída do Reino Unido da União Europeia, em junho de 2016, possivelmente implicará em aspectos do direito internacional do turismo. Esse fato histórico-geopolítico pode, talvez, causar a redução do número de turistas para roteiros ingleses, hipótese que poderia ser investigada no futuro por estudiosos do turismo.

Este estudo nos levou a constatar também que há escassez de produção teórica acerca desta temática, em parte pelos profissionais do direito e em parte por estudiosos do turismo. Nesse contexto, o artigo se insere como sucinta contribuição ao debate no meio acadêmico.

Finalizando, admitimos o inacabamento desta reflexão, porém entendemos que tem havido a valorização do ensino e da pesquisa em turismo no meio acadêmico, algo que tem atraído profissionais de diferentes áreas do conhecimento: advogados, administradores de empresa, economistas, sociólogos, antropólogos, geógrafos e outros. Esperamos que este escrito possa contribuir, em alguma medida, para o debate e a reflexão. Suscitamos, contudo, a abertura às sugestões e às críticas, que são legitimadas como parte do processo de produção científica em turismo, como em qualquer área ou subárea do conhecimento.

\section{REFERÊNCIAS}

ANDRADE, J. V. (2001). Turismo: fundamentos e dimensões. São Paulo: Ática.

BADARÓ, R. A. L. (2006). Direito do turismo: história e legislação no Brasil e no exterior. São Paulo: Editora Senac.

BARRETO, M., Burgos, R., \& Frenkel, D. (2003). Turismo, políticas públicas e relações internacionais. Campinas, SP: Papirus.

BENI, M. (2003). Globalização do turismo. São Paulo: Aleph.

BULL, H. (2002). A sociedade anárquica: um estudo da ordem política mundial. São Paulo: Editora da UnB.

DALLARI, D. A. (2013). Elementos de teoria geral do Estado. São Paulo: Saraiva.

DECRETO no 19.841, de 22 de outubro de 1945. (1945, 23 de outubro). Rio de Janeiro: Diário Oficial da União. Recuperado de http://bit.ly/1qmicop

DELORS, J. (Org.). (2007). Educação: um tesouro a descobrir. São Paulo: Cortez; Unesco.

FLUMIAN, R. (2012). Super revisão: direito internacional. Indaiatuba, SP: Foco.

GIL, A. C. (2010). Como elaborar projetos de pesquisa. São Paulo: Atlas.

HOERNER, J. M. (2001). Geopolítica do turismo. São Paulo: Editora Senac. 
HUNTINGTON, S. P. (1997). O choque de civilizações e a recomposição da ordem mundial. Rio de Janeiro: Objetiva.

LIMA, G. M. (2003). Críticas à teoria das gerações (ou mesmo dimensões) dos direitos fundamentais. Jus Navigandi, 8(173).

MARTÍN, A. M., \& Nogueras, D. J. L. (2010). Instituciones y derecho de la Unión Europea. Madrid: Tecnnos.

MELLO, C. D. A. (2004). Curso de direito internacional público. Rio de Janeiro: Renovar, 2004. MORIN, E. (2005). Educação e complexidades: os sete saberes e outros ensaios. São Paulo: Cortez. NYE, Joseph. (2002). O paradoxo do poder americano: por que a única superpotência do mundo não pode prosseguir isolada. São Paulo: Unesp.

ONU. (2015). Nações Unidas no Brasil. Recuperado de http://www.onu.org.br

OMT. (2016). Código de ética mundial para o turismo. Recuperado de http://bit.ly/2xxBcUV PECEQUILO, C. S. (2004). Introdução às relações internacionais. Petrópolis, RJ: Vozes.

PIERI, V. S. G., \& Panosso Netto, A. (2015). Turismo Internacional: fluxos, destinos e integração regional. Boa Vista, RR: Editora da UFRR.

PINTO, T. S. (2017). Mundo da educação: criação da ONU após a Segunda Guerra Mundial. Recuperado de http://bit.ly/2gatXQ5

PIOVESAN, F. (2010). Direitos humanos e o direito constitucional internacional. São Paulo: Saraiva.

SARFATI, G. (2005). Teoria de relações internacionais. São Paulo: Saraiva.

SILVA, J. A. (2002). Direito ambiental constitucional. São Paulo: Malheiros.

SILVA, L. P. L. (2005). A responsabilidade civil nos contratos de turismo em face do código de defesa do consumidor. São Paulo: Renovar.

SIMUNA. (2015). Conselho de Direitos Humanos das Nações Unidas (UNHRC): guia de estudos. Recuperado de http://bit.ly/2i2rZBP

SOARES do Bem, A. (2005). A dialética do turismo sexual. Campinas, SP: Papirus.

UNESCO. (2001). Declaração universal sobre a diversidade cultural e plano de ação. Recuperado de http://bit.ly/2g1jHWP

UNHCR. (2017). Conselho de direitos humanos. Recuperado de http://bit.ly/1wnId8U WASHINGTON, D.C. (2015). Organização dos Estados Americanos. Recuperado de http://bit.ly/ $2 \mathrm{gu} 2 \mathrm{CFw}$ 